\title{
The Effects of Video Feedback on Coaches' Behavior and the Coach-Athlete Relationship
}

\author{
Mathieu Simon Paul Meeûs \\ Catholic University of Leuven, Belgium \\ Sidónio Serpa \\ Technical University of Lisbon, Portugal \\ Bert De Cuyper \\ Catholic University of Leuven, Belgium
}

\begin{abstract}
This study examined the effects of video feedback on the nonverbal behavior of handball coaches, and athletes' and coaches' anxieties and perceptions. One intervention group ( 49 participants) and one control group (63 participants) completed the Coaching Behavior Assessment System, Coaching Behavior Questionnaire, and Competitive State Anxiety Inventory-2 on two separate occasions, with 7 weeks of elapsed time between each administration. Coaches in the intervention condition received video feedback and a frequency table with a comparison of their personal answers and their team's answers on the CBAS. Repeated-measures ANOVAs showed that over time, athletes in the intervention group reported significantly less anxiety and perceived their coaches significantly more positively compared with athletes in the nonintervention condition. Over time, coaches in the intervention group perceived themselves significantly more positively than coaches in the nonintervention condition. Compared with field athletes, goalkeepers were significantly more anxious and perceived their coaches less positively. It is concluded that an intervention using video feedback might have positive effects on anxiety and coach perception and that field athletes and goalkeepers possess different profiles.
\end{abstract}

Keywords: Nonverbal behavior, anxiety, coach, athlete, video feedback

During competition, coaches react to athlete actions in varying ways. Coaches give verbal feedback and instructions, but they also demonstrate nonverbal behavior.

Mathieu Meeûs and Bert De Cuyper are with the Department of Human Kinesiology at Catholic University of Leuven, Belgium. Sidónio Serpa is with the Faculty of Human Movement at the Technical University of Lisbon, Portugal. 
These verbal and nonverbal coaching behaviors all have an impact on their athletes. Particularly in the youth sport environment, coaches have a major influence on the sport experiences of their athletes. As shown by Passer (1988), critical or punitive feedback from coaches can evoke high levels of negative effect in children who fear failure and disapproval. In contrast, children who perceive their coaches as supportive tend to report higher levels of sport enjoyment and have lower anxiety scores (Smoll, Smith, Barnett, \& Everett, 1993).

\section{Verbal vs. Nonverbal Behavior}

Zuckerman, DePaulo, and Rosenthal (1980) suggested that individuals rely more on the face (nonverbal communication) than on the voice, even when they expect deception. Individuals are less accurate in encoding those messages, however. When verbal and nonverbal messages are contradictory, athletes tend to place more importance on the nonverbal behavior than on the words of the coach. Nonverbal behavior may be a trigger for some athletes to become frustrated, lose focus, or freeze. Ineffective communication can thus occur when the nonverbal behavior does not match the verbal behavior. Some research has suggested that it is most likely that individuals detect deception and "fake" messages by comparing verbal and nonverbal communication channels (Littlepage \& Pineault, 1978), as individuals have more difficulties judging deception from either the verbal or nonverbal channel alone.

Mignault and Chaudhuri (2003), in their research regarding perceptions of dominance and emotion, concluded that various head movements were perceived similarly across individuals. For example, lifting the head up was perceived as more dominant and happy and was associated with greater superiority emotions, while a bowed head was perceived as submissive and sad and was associated with emotions associated with inferiority. DePaulo and Rosenthal (1979) showed that individuals rely much more on visual cues than on verbal cues when assessing positivity. The same result was previously found by Wish (1976), who concluded that individuals use the visual channel for encoding the degree of pleasure or positivity of a message. For encoding intensity level, individuals focused more on the vocal channel.

\section{Coach-Athlete Relationship}

When studying the relationship between coaches and athletes, the meditational model of coach-player relationships (Smoll \& Smith, 1989) has been one of the most commonly used frameworks. In such studies, the main focus has been on athletes' and coaches' perceptions of different coaching behaviors. Specifically, the consequences on performance, satisfaction, and anxiety have been examined. To study coach and athlete interpersonal behaviors, other conceptual models have been developed (Jowett \& Cockerill, 2002; Mageau \& Vallerand, 2003; Poczwardowski, Barott, \& Peregoy, 2002; Wylleman, 2000). However, the nonbehavioral aspects of the coach-athlete relationship (Vergeer, 2000), such as cognitions and emotions, tend to be overlooked. Jowett and Don Carolis (2003) have stated that athletes and coaches can perceive the coach-athlete relationship from two different perspectives. The direct perspective is an athlete's (or coach's) perception of his or her 
personal emotions, cognitions, and behaviors toward a team member or coach (or athlete). The meta-perspective is an athlete's (or coach's) perception of how another team member feels, thinks, and behaves toward him or herself. Research suggests that high scores on emotional closeness, cognitive commitment, and behavioral complementarity in the coach-athlete relationship are associated with higher levels of satisfaction with performance and personal treatment (Jowett \& Don Carolis, 2003), higher levels of team cohesion (Jowett \& Chaundy, 2004), higher levels of harmonious passion toward the activity (as opposed to obsessive passion), and lower levels of role ambiguity in team sports (Olympiou, Jowett, \& Duda, 2004, 2005).

Regarding the coach-athlete relationship, many structured coaching training programs have been developed to increase coaching behaviors, resulting in positive reinforcement and reduce behaviors resulting in punishment and punitive technical instructions (Horn, 1985; Smoll, Smith, \& Hunt, 1978). An example of such a program is the coach effectiveness training of Smith, Smoll, Hunt, and Curtis (1979).

The mastery approach to coaching of Smoll and Smith (2006) has been shown to result in reduced performance anxiety. In addition, Barnett, Smoll, and Smith (1992) found that athletes who had coaches trained in these principles perceived their coaches as providing more positive reinforcement and fewer punishments than athletes with untrained coaches. This resulted in differential dropout rates: $5 \%$ in the trained-coach group vs. $26 \%$ in the untrained-coach group.

Smith, Smoll, and Cumming (2007) tested the effects of a cognitive-behavioral intervention designed to promote a mastery motivational climate on changes in male and female athletes' cognitive and somatic performance anxiety during a basketball season. Athletes who played for coaches trained in the coach effectiveness system showed decreases on all scales of the Sport Anxiety Scale-2 and in total anxiety scores from preseason to late season. In contrast, the athletes in the control group (i.e., with coaches not trained in this system) reported an increase in anxiety over the season. The intervention had equally positive effects on boys' and girls' teams (Smith et al., 2007).

Sousa, Smith, and Cruz (2008) studied an individualized behavioral goal-setting program for coaches. Four selected football coaches with different backgrounds participated. The participants selected three target behaviors that they believed were important to modify after receiving videotaped feedback. Behavioral assessment revealed that two of the coaches achieved positive changes on all three of their targeted behaviors. A third coach improved on two of three targeted behaviors, and the fourth coach did not achieve any of the established goals. This recent research about the nonverbal behavior of coaches focused on how coaches perceived themselves compared with how athletes perceived them. Along this line, the focus of the current study is on the consonance between athletes' perceptions of their coaches and what the coaches believe their athletes think of them. This may be particularly relevant in team sports where coaches are physically close to their athletes, as players are likely to make eye contact with their coaches during games.

The main purpose of the current study was to test the effects of video feedback as an intervention to modify and improve the nonverbal behavior of handball coaches. The hypotheses of this research are (a) over time, athletes in the video feedback condition will show a significantly greater increase in evaluating their coaches positively, compared with athletes in the nonintervention condition; (b) over time, coaches in the video feedback condition will show a significantly greater 
increase in perceiving themselves positively, compared with coaches in the nonintervention condition; and (c) over time, athletes in the video feedback condition will show a significantly greater decrease in anxiety, compared with athletes in the nonintervention condition.

\section{Method}

\section{Sport Selection}

The choice to perform this research using the sport of handball was based on three factors: (a) handball is one of the largest team sports for men and women in Portugal; (b) the sport fulfils the previously noted conditions (i.e., team sport, coach is physically close to the athletes, possibility of calling a timeout); (c) there was a willingness from coaches of high-level clubs to participate in this study; and (d) numerous studies in Europe are conducted using the sport of handball (Broch, 2003; De Backer, Vande Broek, \& Ceux, 2008; Dosil, 2006; Van Buggenhout, Papaioannou, \& Vanden Auweele, 2003).

\section{Participants}

A total of 93 handball players and their nine coaches, belonging to nine teams from three different clubs, participated in the study. They were divided into one video feedback and one nonintervention condition. All teams competed at the highest level for their age groups.

The video feedback condition was comprised of 45 athletes and four coaches, made up of one female and three male teams. Athletes consisted of 12 females (26.67\%) and 33 males $(73.33 \%)$, ranging in age from 13 to 18 years $(M=14.89$, $S D=1.53)$. The average age of the athletes was 14.52 years for males $(S D=1.58)$ and 15.92 years for females $(S D=0.64)$. One female coach and three male coaches participated in the intervention group, with ages ranging from 25 to 46 years $(M$ $=31.5, S D=9.75)$.

The nonintervention control condition was comprised of 58 athletes and five coaches, made up of three female and two male teams. Athletes consisted of 37 females $(63.79 \%)$ and 21 males $(36.21 \%)$, ranging in age from 13 to 18 years $(M$ $=14.56, S D=1.22)$. The average age of the athletes was 15.10 years for males $(S D$ $=1.26)$ and 14.27 years for females $(S D=1.21)$. Three female coaches and two male coaches participated in the nonintervention group, with ages ranging from 23 to 41 years $(M=28.8, S D=7.05)$.

\section{Procedures}

Timeline. The athletes in the video feedback and nonintervention conditions received a document explaining the purpose of the study, signed by the first and second authors. The athletes delivered the documents to their coaches after they had been completed and signed by their parents. All athletes received permission from their parents to participate and delivered the documents to their coaches. The study consisted of five phases: 
1. First completion of the questionnaires, which occurred at the beginning of the last training session before the recorded game. Athletes and coaches were separated while completing the questionnaires. In addition, the participants were informed about the confidentiality of all data.

2. Video recording of one or two games.

3. Intervention with the coaches in the video feedback condition. The intervention was conducted after analyzing the first questionnaires and the recorded game, which was approximately one week after the first questionnaire administration. The teams in the nonintervention condition did not receive any intervention during this research program.

4. Second completion of the questionnaires. This administration occurred 7 weeks after the initial completion of the questionnaires. Athletes and coaches were once again separated while completing the questionnaires.

5. Feedback for the coaches.

Observation Protocol. The observation protocol was developed by the researchers in accordance with handball coaches; it was then jointly reviewed by them and qualified observers after a trial. The trial situation was a season game of one of the teams participating in the research program. The observers were asked to write down the number of times they observed each coaching behavior. The trial took place before the first actual game was recorded. After this, the researchers improved the protocol.

All games were recorded by the same researcher. Two other observers then coded the behaviors of the coaches during games. The video tapes were first used to solve coding discrepancies between the observers. The few situations where disagreements occurred were not used during the intervention, however. After coding, the videos were then used as part of the intervention.

Observer reliability drift is the tendency of the two observers to begin to agree with each other, achieving unusually high levels of reliability, which in turn may decrease the reliability and validity of the observed behaviors (Kazdin, 1982). To avoid observer reliability drift during the study, the observers met to discuss coding issues and to receive feedback concerning the accuracy of their observations. In addition, they were seated in the stands in a manner that did not allow for direct contact between them during their observations. The coaches' results were revealed only at the end of this research to the two observers. Frequency tables were created comparing answers from the athletes to answers from the coaches. If at least four athletes provided a different answer than their coach, the questions were submitted to the frequency tables.

Analyzing Software. The games were recorded by two digital video (DV) cameras; one camera was focused on the coach and the other was focused on the game. These DV tapes were captured on the hard drive in AVI (Audio Video Interleave) format using Auto Movie Creator (AMC). AMC is a movie-editing program that allows for importing movies, cutting, and/or adding visual and sound effects. Using the storyboard of AMC, the movies of the coach and the game were cut. Adding the split-screen option, these two movies could be viewed simultaneously. The result was a split-screen with the left side of the screen focusing on the coach and the 
right of the screen displaying the game. By exporting the movie from AMC to a computer, the actual new split-screen video was created and saved as an MPEG file with according DVD options. Creating the movie for the intervention in this way made it possible to burn a DVD for each coach with a split-screen video of his or her recorded game.

The movies were adjusted in such a way that the exact beginning of a coach's emotional or behavioral display could be linked to the exact moment in the game that triggered the emotion or behavior. For instance, in a situation where an athlete misses a shot to the goal, the coach displays frustration by placing his hands in front of his face; after this, he begins screaming and displays an angry facial expression toward the athlete. By showing this to the coach, he could become aware of the way he expressed his anger and disappointment and of how he did not positively reinforce the team in general despite sound attack action.

Intervention. The first author conducted all interventions with the coaches in the intervention group. The researcher illustrated how the athletes perceived their coaches and how the coaches thought they were perceived by their athletes. During the intervention, it was not mentioned which aspects of a coach's behavior required modification. Therefore, each coach was free to choose for him or herself which of the presented data points were most useful or of greatest importance. It is possible that this strategy allows the coaches to develop greater motivation to change. The intervention was based on the athletes' answers on the Coach Behavior Assessment Scales, compared with the answers given by the coach. The answers on questions regarding the coach's behavior during games and how that behavior impacted the athletes were the basis for the researchers to locate fragments on the video that illustrated this behavior during home games. Then, a selection of scenes was shown to the coach to confront him or her with these behaviors during the game, timeouts, and halftime break. It was assumed that this procedure would have a stronger effect on coaches than merely verbally informing them about their behaviors. Using a summary information sheet, coaches were also informed about the questions on which they and their athletes answered differently. The coaches' and athletes' answers could be found next to each question. After this intervention, the coaches could take this information sheet home to use it in the future. The intervention lasted approximately $1 \mathrm{hr}$ and $30 \mathrm{~min}$. Then, for the second measurement, the Coach Effectiveness Training Questionnaire was delivered to check what the coaches thought about the intervention. After analyzing the results, a new session was organized aiming at informing the coaches about the results of the research.

\section{Measures}

The CBAS Player Perceived Behavior Scale (CBAS-PBS) was developed by Smith et al. (1979) to evaluate athletes' perceptions of their coaches' behaviors. The questionnaire assesses 12 observed behaviors of the coach that are classified into two groups: (a) reactive behaviors in response to situations concerning desirable performance or effort, mistakes, or misbehavior (including the following dimensions: reinforcement, nonreinforcement, mistake-contingent encouragement, mistake-contingent technical instruction, punishment, punitive technical instruction, ignoring mistakes, and keeping control) and (b) coach-initiated spontaneous behaviors (including the following dimensions: general technical instruction, 
general encouragement, organization and general communication). The athletes answered how frequently their coach behaves a certain way by using a 7-point Likert scale ranging from 1 (never) to 7 (always). In this research program, a special version was also used to assess how the coaches think their athletes perceive them according to the CBAS items.

The Coaching Behavior Questionnaire developed by Kenow and Williams (1992) was used to evaluate five specific aspects of the coaches' behavior: supportiveness, communication, somatic effects of coaches' behavior, emotional control and composure, and cognitive effects of coaches' behavior. Answers are noted on a 5-point Likert scale ranging from 1 (strongly disagree) to 5 (strongly agree). The original questionnaire was composed of 28 items (20 actual and 8 fillers), but was reduced to 23 items (20 actual and 3 fillers). Negatively worded items are reverse weighted so that higher total scores reflect a more positive evaluation of coaches' game behaviors. The potential scores range from 20 to 100 . The athletes and coaches were asked to complete the questionnaire as if they were going to play an important game in the championship.

The Competitive State Anxiety Inventory-2 (CSAI-2), developed by Martens, Burton, Vealey, Bump, and Smith (1990), was also used. This questionnaire measures cognitive and somatic anxiety, as well as self-confidence in regard to a competitive situation, on a 4-point Likert scale ranging from 1 (never) to 4 (very mисh). Once again, the athletes were asked to complete the questionnaire as if they were going to play an important game in the championship.

According to Kenow and Williams (1999), compatibility is defined as "the degree to which your goals, personality, and beliefs are consistent with your coach's goals, personality, and beliefs" (p. 254). One compatibility measure was therefore used. The athletes were asked to rate how compatible they believed they were with their coach on a 9-point Likert scale ranging from 1 (not compatible at all) to 9 (very compatible).

The Coach Effectiveness Training Questionnaire (CETQ), developed by Sousa et al. (2008), was completed by the coaches in the intervention group during posttest to have a quantitative evaluation of the program. Taking the coaches' opinions into consideration, a first evaluation of the intervention was possible. The questionnaire contained 11 items covering various aspects of the program and the perceived value to the coach. Responses were based on a 6-point Likert scale ranging from 1 (excellent) to 6 (very poor).

\section{Results}

\section{Data Analytic Procedures}

For the statistical analysis, the Mann Whitney- $U$ test was set for the treatment of the CBAS questionnaire to determine which questions coaches and players answered differently. The Mann Whitney- $U$ tests were calculated on each team separately, in both conditions, because the CBAS asks about the specific coach-athlete relationship within a team.

A second Mann Whitney- $U$ test was calculated on the same CBAS questionnaire to study the relationship between the goalkeepers and the other athletes on a team. 
Third and fourth Mann Whitney- $U$ tests were performed on the Compatibility Measure to compare the same variables.

Two $\times 2 \times 2 \times 2$ repeated-measures ANOVAs were calculated on the coaching behavior questionnaires of the athletes with regard to condition (video feedback vs. nonintervention), position on the field (goalkeeper vs. field athlete), and gender (male vs. female). In addition to the between-subjects variables, time (pretest, posttest) as a within-subjects variable was tested.

Two $\times 2$ repeated-measures ANOVAs were calculated on the coaching behavior questionnaires of the coaches with regard to condition (video feedback vs. nonintervention) as a between-subjects variable and time (pretest, posttest) as a within-subjects variable.

Two $\times 2 \times 2 \times 2$ repeated-measures ANOVAs were calculated on the Competitive State Anxiety Inventory-2 (CSAI-2) with regard to condition (video feedback vs. nonintervention), position on the field (goalkeeper vs. field athlete), and gender (male vs. female) as between-subjects variables and time (pretest, posttest) as a within-subjects variable.

The main dependent variables of this study are the variations in the total scores on the Coach Behavior Questionnaire and the Competitive State Anxiety Inventory- 2 of the athletes and coaches at pretest and posttest, and in addition, the number of questions that were answered differently by athletes and coaches on the Coach Behavior Assessment Scale.

\section{Descriptives}

One-way ANOVAs showed that between athletes of the video feedback and nonintervention condition, no significant differences were found with respect to age: $F(1,102)=1.388, p=0.241$. In addition, a chi-square test revealed that there were significant differences between athletes with respect to gender: $\chi^{2}=14.004, p<$ .001 . In addition, a significant difference between the video feedback condition and nonintervention condition was found with respect to the number of years of athletic involvement (Table 1), with the video feedback condition reporting significantly more years of athletic experience.

One-way ANOVAs also showed that between coaches of the video feedback and nonintervention condition, no significant differences were found with respect

Table 1 Differences in Background Characteristics Between the Video Feedback (VFC) and Nonintervention Condition (NIC)

\begin{tabular}{lcccc}
\hline Characteristics & $\begin{array}{c}\text { VFC Mean } \\
(\& S D)\end{array}$ & $\begin{array}{c}\text { NIC Mean } \\
(\& S D)\end{array}$ & F & p-value \\
\hline $\begin{array}{l}\text { Age of the athletes } \\
\text { Number of years as }\end{array}$ & $14.89(1.53)$ & $14.57(1.23)$ & 1.338 & 0.24 \\
an athlete & $5.07(2.89)$ & $2.88(1.92)$ & 21.224 & $<0.001$ \\
$\begin{array}{l}\text { Age of the coaches } \\
\text { Number of years as a }\end{array}$ & $31.5(9.75)$ & $28.8(7.05)$ & 0.234 & 0.64 \\
coach & $11.25(12.84)$ & $6.00(3.74)$ & 0.778 & 0.41 \\
\hline
\end{tabular}

Note. Means of the video feedback and nonintervention condition of one characteristic in a row differ significant at $p \leq .05$ in one-way ANOVA analyses. 
to age, $F(1,8)=0.234, p=0.643$, and with respect to number of years as a coach (Table 1). In addition, a chi-square test revealed that between coaches of the video feedback and nonintervention condition, there were no significant differences among coaches with respect to gender, $\chi^{2}(1,9)=1.103, p=0.147$.

\section{Coach Behavior Assessment Scale (CBAS)}

A comparison was made between the answers given by participants during the first administration at the beginning of the research program and answers given during the second administration at the end of the research program. As noted previously, the second administration was conducted 7 weeks after the intervention with the coaches.

Table 2 illustrates that the number of questions answered differently by athletes and coaches in the video feedback condition decreased from 16 (out of 104) to $6(0.154 \%$ vs. $0.058 \%)$. In contrast, the number of questions that were answered differently by the nonintervention participants increased from 15 (out of 130) to $16(0.115 \%$ vs. $0.123 \%)$. Comparing the answers from the first administration to the answers from the second administration, the number of questions that were answered differently by the goalkeepers and the field athletes in the video feedback condition reduced from 23 items to 11 items. The number of questions that were

\section{Table 2 Overview of Number of Different Answers on the CBAS Questionnaire or Compatibility Measure (CM)}

\begin{tabular}{llcc}
\hline & Athletes vs. coaches & $\begin{array}{c}\text { Start of } \\
\text { Research }\end{array}$ & $\begin{array}{c}\text { End of } \\
\text { Research }\end{array}$ \\
\hline Video feedback Team 1 & Goalkeepers vs. other team members & 10 & 2 \\
& Athletes vs. coaches & 3 & 2 \\
Video feedback Team 2 & Goalkeepers vs. other team members & 1 & 0 \\
& Athletes vs. coaches & 1 & 1 \\
Video feedback Team 3 & Goalkeepers vs. other team members & 6 & 3 \\
Video feedback Team 4 & Athletes vs. coaches & 6 & 3 \\
& Goalkeepers vs. other team members & 6 & 5 \\
Nonintervention Team 1 & Athletes vs. coaches & 5 & 3 \\
& Goalkeepers vs. other team members & 3 & 3 \\
Nonintervention Team 2 & Athletes vs. coaches & 1 & 6 \\
& Goalkeepers vs. other team members & 0 & 1 \\
Nonintervention Team 3 & Athletes vs. coaches & 3 & 4 \\
& Goalkeepers vs. other team members & 5 & 5 \\
Nonintervention Team 4 & Athletes vs. coaches & 5 & 3 \\
& Goalkeepers vs. other team members & 4 & 5 \\
Nonintervention Team 5 & Athletes vs. coaches & 1 & 0 \\
& Goalkeepers vs. other team members & 4 & 4 \\
\hline
\end{tabular}


answered differently by the goalkeepers and the field athletes in the nonintervention condition increased from 16 items to 18 items.

\section{Results Based on Hypotheses}

Hypothesis 1 suggested that over time, athletes in the video feedback condition would show a significantly greater increase in evaluating their coaches positively, compared with athletes in the nonintervention condition.

As can be seen in Table 3, over time, athletes in the video feedback condition evaluated their coaches significantly more positively, compared with athletes in the nonintervention condition. Contrast analyses revealed that athletes in the video feedback condition demonstrated a more positive perception of their coach at the end of the research program, compared with the beginning of the program. This trend was not found among the nonintervention group.

As illustrated in Table 4, athletes in the video feedback and in the nonintervention condition evaluated their coaches in an equally positive manner at the begin-

\section{Table 3 Differences in Scores on the Coach Behavior Questionnaire (CBQ) Between the Video Feedback (VFC) and Nonintervention Conditions}

\begin{tabular}{|c|c|c|c|c|c|c|}
\hline \multirow[b]{2}{*}{ Variables } & \multicolumn{2}{|c|}{ VFC } & \multicolumn{2}{|c|}{ NIC } & \multirow[b]{2}{*}{$\begin{array}{c}F \\
(\& d f)\end{array}$} & \multirow[b]{2}{*}{$P$ value } \\
\hline & $\begin{array}{c}\text { Mean } \\
(\& S D) \\
\text { Start of } \\
\text { Research }\end{array}$ & $\begin{array}{c}\text { Mean } \\
(\& S D) \\
\text { End of } \\
\text { Research }\end{array}$ & $\begin{array}{c}\text { Mean } \\
(\& S D) \\
\text { Start of } \\
\text { Research }\end{array}$ & $\begin{array}{c}\text { Mean } \\
(\& S D) \\
\text { End of } \\
\text { Research }\end{array}$ & & \\
\hline Time & & & & & $\begin{array}{c}38.175 \\
(95)\end{array}$ & $<.001$ \\
\hline $\begin{array}{l}\text { Time } \\
* \text { Condition }\end{array}$ & $\begin{array}{l}62.53 \\
(6.52)\end{array}$ & $\begin{array}{l}73.42 \\
(5.98)\end{array}$ & $\begin{array}{l}64.67 \\
(6.51)\end{array}$ & $\begin{array}{l}66.14 \\
(5.39)\end{array}$ & $\begin{array}{c}13.426 \\
(95)\end{array}$ & $<.001$ \\
\hline
\end{tabular}

Note. Means of the video feedback and nonintervention condition of one characteristic in a row differ significant at $p \leq .05$ in repeated-measures ANOVA analyses, $\mathrm{df}=$ degrees of freedom.

Table 4 Differences in Scores on the Coach Behavior Questionnaire (CBQ) Between the Athletes in the Video Feedback (VFC) and Nonintervention Condition at the Beginning and End of the Research Program

\begin{tabular}{lccccc}
\hline Time & $\begin{array}{c}\text { VFC Mean } \\
(\& S D)\end{array}$ & $\begin{array}{c}\text { NIC Mean } \\
(\& S D)\end{array}$ & $\mathbf{F}$ & $\begin{array}{c}\text { Degrees of } \\
\text { Freedom }\end{array}$ & p-value \\
\hline $\begin{array}{l}\text { Beginning } \\
\text { of research }\end{array}$ & $62.53(6.52)$ & $64.67(6.51)$ & 2.735 & 95 & 0.001 \\
$\begin{array}{l}\text { End of } \\
\text { research }\end{array}$ & $73.42(5.98)$ & $66.14(5.39)$ & 42.071 & 95 & $<0.001$ \\
\hline
\end{tabular}

Note. Means of the video feedback and nonintervention condition of one characteristic in a row differ significant at $p \leq .05$ in one-way ANOVA analyses. 
ning of the research program. At the end of the program, however, a significant difference in coach perception scores between the video feedback condition and the nonintervention condition was found. At the completion of the program, the video feedback condition evaluated their coaches significantly more positively, compared with the nonintervention condition.

Examining these results in more detail, we found that all goalkeepers evaluated their coaches significantly less positively compared with all field athletes (regardless of condition), both at the beginning and at the end of the research program (Table 5 ). As can be seen in Table 6 , the goalkeepers evaluated their coaches significantly less positively compared with the field athletes in both the video feedback condition and the nonintervention condition, both at the beginning and at the end of the research program.

Table 5 Differences in Scores on the Coach Behavior Questionnaire (CBQ) Between the Goalkeepers and Field Athletes

\begin{tabular}{lllccc}
\hline Time & $\begin{array}{c}\text { Goalkeepers } \\
\text { Mean (\&SD) }\end{array}$ & $\begin{array}{c}\text { Field } \\
\text { Athletes } \\
\text { Mean (\&SD) }\end{array}$ & F & $\begin{array}{c}\text { Degrees of } \\
\text { Freedom }\end{array}$ & p-value \\
\hline $\begin{array}{l}\text { Beginning } \\
\text { of research }\end{array}$ & $56.13(4.81)$ & $65.03(5.93)$ & 30.315 & 102 & $<0.001$ \\
$\begin{array}{l}\text { End of } \\
\text { research }\end{array}$ & $62.20(5.52)$ & $70.53(6.12)$ & 24.415 & 102 & $<0.001$ \\
\hline
\end{tabular}

Note. Means of the video feedback and nonintervention condition of one characteristic in a row differ significant at $p \leq .05$ in one-way ANOVA analyses.

Table 6 Differences in Scores on the Coach Behavior Questionnaire (CBQ) Between Goalkeepers and Field Athletes in the Video Feedback and Nonintervention Condition, Separately

\begin{tabular}{lcccc}
\hline & \multicolumn{2}{c}{ Video Feedback Condition } & & \\
\cline { 2 - 3 } Time & $\begin{array}{c}\text { Goalkeepers Mean } \\
(\& S D)\end{array}$ & $\begin{array}{c}\text { Field Athletes } \\
\text { Mean (\&SD) }\end{array}$ & $\mathbf{F ~ ( \& ~ d f )}$ & p value \\
\hline $\begin{array}{l}\text { Beginning } \\
\text { of research }\end{array}$ & $55.57(1.40)$ & $63.82(6.27)$ & $11.773(44)$ & 0.001 \\
$\begin{array}{l}\text { End of } \\
\text { research }\end{array}$ & $64.71(2.43)$ & $75.03(4.96)$ & $2.559(44)$ & $<0.001$ \\
\hline \multicolumn{4}{c}{ Nonintervention Condition } \\
\cline { 2 - 3 } & $\begin{array}{c}\text { Goalkeepers Mean } \\
(\& S D)\end{array}$ & $\begin{array}{c}\text { Field Athletes } \\
\text { Mean (\&SD) }\end{array}$ & $\mathbf{F ~ ( \& ~ d f )}$ & p value \\
\hline $\begin{array}{l}\text { Beginning } \\
\text { of research }\end{array}$ & $\begin{array}{c}56.63(6.63) \\
\begin{array}{l}\text { End of } \\
\text { research }\end{array}\end{array}$ & $65.96(5.54)$ & $18.575(57)$ & $<0.001$ \\
\hline
\end{tabular}

Note. Means of the video feedback and nonintervention condition of one characteristic in a row differ significant at $p \leq .05$ in one-way ANOVA analyses, $\mathrm{df}=$ degrees of freedom. 
Hypothesis 2 suggested that after the intervention, coaches in the video feedback condition would perceive themselves more positively than coaches in the nonintervention condition. In fact, as illustrated in Table 7, at the end of the research program, coaches in the video feedback condition perceived themselves significantly more positively, compared with coaches in the nonintervention condition.

Hypothesis 3 suggested that over time, athletes in the video feedback condition would demonstrate a significantly greater decrease in anxiety, compared with athletes in the nonintervention condition. Results (see Table 8) in fact revealed that athletes in the video feedback condition showed a significantly greater decrease in feelings of anxiety, compared with athletes in the nonintervention condition. Athletes in the video feedback condition obtained lower anxiety scores at the end of the research program than at the beginning of the program. In the nonintervention condition, the average anxiety scores at the beginning and the end of the research program did not differ significantly from each other. As can be seen in Table 9, no significant differences were found at the beginning of the research program between the video feedback and the nonintervention conditions. This means that at the start of the program, athletes reported equal levels of anxiety. After the intervention,

Table 7 Differences in Scores on the Coach Behavior Questionnaire (CBQ) Between Coaches in the Video Feedback (VFC) and Nonintervention Condition (NIC)

\begin{tabular}{|c|c|c|c|c|c|c|}
\hline \multirow[b]{2}{*}{ Variables } & \multicolumn{2}{|c|}{ VFC } & \multicolumn{2}{|c|}{ NIC } & \multirow[b]{2}{*}{$\begin{array}{c}F \\
(\& d f)\end{array}$} & \multirow[b]{2}{*}{$\begin{array}{c}p \\
\text { value }\end{array}$} \\
\hline & $\begin{array}{l}\text { Mean (\&SD) } \\
\text { Beginning } \\
\text { of Research }\end{array}$ & $\begin{array}{c}\text { Mean (\&SD) } \\
\text { End of } \\
\text { Research }\end{array}$ & $\begin{array}{l}\text { Mean (\&SD) } \\
\text { Beginning } \\
\text { of Research }\end{array}$ & $\begin{array}{c}\text { Mean (\&SD) } \\
\text { End of } \\
\text { Research }\end{array}$ & & \\
\hline Time & & & & & $5.605(7)$ & 0.05 \\
\hline $\begin{array}{l}\text { Time * } \\
\text { Condition }\end{array}$ & $\begin{array}{l}70.75 \\
(8.02)\end{array}$ & $\begin{array}{l}77.75 \\
(8.30)\end{array}$ & $\begin{array}{l}68.80 \\
(3.77)\end{array}$ & $\begin{array}{l}68.80 \\
(2.77)\end{array}$ & $5.605(7)$ & 0.05 \\
\hline
\end{tabular}

Note. Means of the video feedback and nonintervention condition of one characteristic in a row differ significant at $p \leq .05$ in repeated-measures ANOVA analyses, $\mathrm{df}=$ degrees of freedom.

Table 8 Differences in Scores on the Competitive State Anxiety Inventory-2 (CSAI-2) for Athletes in the Video Feedback (VFC) and Nonintervention Condition (NIC)

\begin{tabular}{lcccccccc}
\hline & \multicolumn{2}{c}{ VFC } & & \multicolumn{2}{c}{ NIC } & & \\
\cline { 2 - 3 } & $\begin{array}{c}\text { Mean (\&SD) } \\
\text { Beginning } \\
\text { of Research }\end{array}$ & $\begin{array}{c}\text { Mean (\&SD) } \\
\text { End of } \\
\text { Research }\end{array}$ & & $\begin{array}{c}\text { Mean (\&SD) } \\
\text { Beginning } \\
\text { of Research }\end{array}$ & $\begin{array}{c}\text { Mean (\&SD) } \\
\text { End of } \\
\text { Research }\end{array}$ & $\begin{array}{c}\text { F } \\
\text { (\& df) }\end{array}$ & $\begin{array}{c}\boldsymbol{p} \\
\text { value }\end{array}$ \\
\hline Time & & & & & $9.499(95)$ & 0.003 \\
Time* & 59.11 & 50.76 & & 58.09 & 59.05 & 4.104 & \\
Condition & $(9.14)$ & $(8.04)$ & & $(10.07)$ & $(8.29)$ & $(95)$ & 0.046 \\
\hline
\end{tabular}

Note. Means of the video feedback and nonintervention condition of one characteristic in a row differ significant at $p \leq .05$ in repeated-measures ANOVA analyses. 
however, the video feedback condition reported significantly lower anxiety scores than the nonintervention condition.

Looking at these results in greater detail, analyses showed that the goalkeepers in the video feedback condition were significantly more anxious than field athletes at both the beginning and the end of the research program. In the nonintervention condition, the goalkeepers were only significantly more anxious at the beginning of the program, but were not at the end (Table 10).

Table 9 Differences in Scores on the Competitive State Anxiety Inventory-2 (CSAI-2) Between the Athletes in the Video Feedback (VFC) and Nonintervention Condition (NIC) at the Beginning and End of the Research Program

\begin{tabular}{lccccc}
\hline Time & $\begin{array}{c}\text { VFC Mean } \\
\text { (\&SD) }\end{array}$ & $\begin{array}{c}\text { NIC Mean } \\
\text { (\&SD) }\end{array}$ & F & $\begin{array}{c}\text { Degrees of } \\
\text { Freedom }\end{array}$ & $\boldsymbol{p}$ value \\
\hline $\begin{array}{l}\text { Beginning } \\
\text { of research }\end{array}$ & $59.11(9.14)$ & $58.09(10.07)$ & 0.284 & 102 & 0.595 \\
$\begin{array}{l}\text { End of } \\
\text { research }\end{array}$ & $50.76(8.04)$ & $59.05(8.29)$ & 26.053 & 102 & $<0.001$ \\
\hline
\end{tabular}

Note. Means of the video feedback and nonintervention condition of one characteristic in a row differ significant at $p \leq .05$ in one-way ANOVA analyses, $\mathrm{df}=$ degrees of freedom.

Table 10 Differences in Scores on the Competitive State Anxiety Inventory-2 (CSAI-2) Between Goalkeepers and Field Athletes in the Video Feedback and Nonintervention Condition, Separately

\begin{tabular}{lcccc}
\hline & \multicolumn{2}{c}{ Video Feedback Condition } & & \\
\cline { 2 - 3 } Time & $\begin{array}{c}\text { Goalkeepers } \\
\text { Mean (\&SD) }\end{array}$ & $\begin{array}{c}\text { Field Athletes } \\
\text { Mean (\&SD) }\end{array}$ & F (\& df) & p value \\
\hline $\begin{array}{l}\text { Beginning } \\
\text { of research }\end{array}$ & $69.71(4.50)$ & $57.16(8.42)$ & $14.612(44)$ & $<0.001$ \\
$\begin{array}{l}\text { End of } \\
\text { research }\end{array}$ & $59.14(2.27)$ & 49.21 (7.78) & $11.08(44)$ & 0.002 \\
\hline & \multicolumn{2}{c}{ Nonintervention Condition } & & \\
\cline { 2 - 3 } & $\begin{array}{l}\text { Goalkeepers } \\
\text { Mean (\&SD) }\end{array}$ & $\begin{array}{c}\text { Field Athletes } \\
\text { Mean (\&SD) }\end{array}$ & F (\& df) & p value \\
\hline $\begin{array}{l}\text { Beginning } \\
\text { of research }\end{array}$ & $68.25(9.04)$ & $56.46(9.32)$ & $11.124(57)$ & 0.002 \\
$\begin{array}{l}\text { End of } \\
\text { research }\end{array}$ & $63.63(7.09)$ & $58.32(8.29)$ & $2.921(57)$ & 0.093 \\
\hline
\end{tabular}

Note. Means of the experimental and control group of one characteristic in a row differ significant at $p \leq .05$ in one-way ANOVA analyses, $\mathrm{df}=$ degrees of freedom. 


\section{Coach Effectiveness Training Questionnaire}

Table 11 shows the individual coach evaluations of the interventions based on their responses to the Coach Effectiveness Training Questionnaire (Sousa et al., 2008). Coaches rated all aspects of the intervention positively, considered the intervention useful, and expected that it would enhance their relationships with their athletes.

\section{Discussion}

When reviewing the stated hypotheses, the results of this research program were mostly in line with our own predictions. Hypothesis 1: Over time, athletes in the video feedback condition showed a significantly greater increase in evaluating their coaches positively, compared with athletes in the nonintervention condition. Hypothesis 2: Over time, coaches in the video feedback condition showed a significantly greater increase in positive self-perception, compared with coaches in the nonintervention condition. Hypothesis 3: Over time, athletes in the video feedback condition showed a significantly greater decrease in anxiety, compared with athletes in the nonintervention condition. These findings may potentially suggest that the athletes' negative perceptions of their coaches might be an important contributor to athletes' anxiety. Therefore, coaches' behaviors during competition may be

\section{Table 11 Individual Coaches' Evaluations of the CET Intervention}

\begin{tabular}{|c|c|c|c|c|}
\hline Questions & $\begin{array}{c}\text { Coach } \\
1\end{array}$ & $\begin{array}{c}\text { Coach } \\
2 \\
\end{array}$ & $\begin{array}{c}\text { Coach } \\
3 \\
\end{array}$ & $\begin{array}{c}\text { Coach } \\
4\end{array}$ \\
\hline 1. The intervention as a whole was & 2 & 1 & 2 & 3 \\
\hline 2. Clarity of intervention objectives was & 2 & 1 & 2 & 2 \\
\hline $\begin{array}{l}\text { 3. Organization of intervention atmosphere for } \\
\text { learning was }\end{array}$ & 1 & 1 & 1 & 2 \\
\hline $\begin{array}{l}\text { 4. Quality of the individual session for learning } \\
\text { was }\end{array}$ & 1 & 1 & 2 & 2 \\
\hline $\begin{array}{l}\text { 5. Interest and usefulness of the intervention to } \\
\text { apply in a daily practice }\end{array}$ & 1 & 1 & 1 & 1 \\
\hline $\begin{array}{l}\text { 6. Qualifications and knowledge of intervention } \\
\text { leader was }\end{array}$ & 2 & 2 & 2 & 2 \\
\hline 7. Quality of the answers' leader to your questions & 2 & 2 & 2 & 3 \\
\hline 8. Amount you learned in this intervention was & 2 & 1 & 2 & 2 \\
\hline $\begin{array}{l}\text { 9. Your degree of motivation to apply what you } \\
\text { learned in this intervention }\end{array}$ & 2 & 1 & 2 & 1 \\
\hline $\begin{array}{l}\text { 10. Expected value of the intervention for improv- } \\
\text { ing your coaching }\end{array}$ & 1 & 1 & 2 & 3 \\
\hline $\begin{array}{l}\text { 11. Anticipated effect that your improvements will } \\
\text { have on your athletes }\end{array}$ & 2 & 1 & 3 & 3 \\
\hline
\end{tabular}

Note. Scale is from 1 to 6; 1 (excellent), 2 (very good), 3 (good), 4 (average), 5 (poor), 6 (very poor). 
influential in reducing athletes' anxiety (Baker, Côte, \& Hawes, 2000). These possibilities await further empirical exploration. Of note, the athletes' perceptions of their coaches were not significantly different for male and female athletes, which supports the findings of Hoffman (2000).

The difference between goalkeepers and field athletes may support the idea that goalkeepers have an isolated position on the team, which is supported by the significantly different scores on coach perception, both at the beginning and at the end of the research program, and among participants in both the video feedback and the nonintervention conditions. This idea is also supported by significant differences in anxiety scores among the video feedback condition when comparing the beginning and the end of the program, as well as by significant differences in anxiety scores when comparing the video feedback and the nonintervention conditions at the beginning of the program. During the analyses of the CBAS questionnaires and the recorded games, it can be observed that the coaches often provided little attention to the goalkeepers. During the interventions, the four coaches recognized this tendency and justified these actions by suggesting that handball is a game that changes quickly from offense to defense. Therefore, they stated that they often forget about the goalkeeper and worry more about the attacking and defending strategies of the field athletes. This may be supported by (a) the decrease in the number of questions that were answered differently by the goalkeepers and field athletes in the video feedback condition and (b) the increase in the number of questions that were answered differently by goalkeepers and field athletes in the nonintervention condition.

It should be stated that the positive effects noted from this research program were obtained by implementing one intervention and inserting a 7-week gap between pretest and posttest. Coaches were also given a DVD that provided a split-screen of both the game and his or her behavior during the game and sheets with the discussed behaviors. Alongside each of the discussed behaviors, the exact time of the respective behavior was noted. Future research might test a more intensive intervention that includes more sessions and for a longer duration to verify if stronger effects would be achieved.

In addition, the coaches evaluated the intervention positively. They considered the behavioral feedback informative and useful and indicated that they want to continue applying what they learned during the intervention. The coaches mentioned that they need to be more aware of the effects of their behaviors on their players. These results support the findings of Sousa et al. (2008), who stated, "additional social validation could be obtained by additional questions about the impact of the intervention on specific practices and open-ended questions about how coaches believed they were affected by the CET program" (p. 272; see also Greenspan \& Feltz, 1989; Kazdin, 1981).

Also of importance, this is one of the first studies to include the coach's behavior during timeouts and halftime breaks in the dressing room. Changed behaviors of coaches in the video feedback condition might have contributed to the increase in coach perception scores and the decrease in anxiety scores among athletes in the video feedback condition. A large portion of the professional literature has discussed the "ideal" or desired behavior of a coach (Deveney, 2007; Pavlovic, 2008; Zetou, Kourtesis, Giazitzi, \& Michalopoulou, 2008). Research has yet to focus on the level of athletes' anxiety during timeouts and halftimes, however. 


\section{Limitations}

A limitation of this study is that athletes in the nonintervention condition reported significantly less athletic experience. This may have resulted in a reduced ability to notice changes in the coach's behavior. It is possible that these athletes may be in a learning phase during which they are more focused on learning handball skills. Therefore, they may be more egocentric than the athletes in the video feedback condition, who might be further along in their development as handball players and may thus be more capable of focusing on teammates, coaches, etc. While this is speculative, to avoid this participant difference in future research, caution should be taken to ensure that participants demonstrate matched athletic experience.

\section{Conclusion}

The present study lends support to the aforementioned hypotheses. Over time, and comparing the video feedback condition to the nonintervention condition, it can be concluded that video feedback can help lower anxiety and increase positive coach perception among handball athletes, as well enhance positive self-perception among coaches. In addition, a significant difference in anxiety and coach perception scores between goalkeepers and field athletes was found. Further research is needed to corroborate these findings and to expand them to other sports. In addition, future research might investigate coaches' total behavior during games as well as behavior during practice sessions, as these are two different settings with unique demands (different stress levels, task vs. goal oriented, etc.).

\section{References}

Baker, J., Côte, J., \& Hawes, R. (2000). The relationship between coaching behaviors and sport anxiety in athletes. Journal of Science and Medicine in Sport, 3(2), 110-119.

Barnett, N.P., Smoll, F.L., \& Smith, R.E. (1992). Effects of enhancing coach-athlete relationships on youth sport attrition. The Sport Psychologist, 6, 111-127.

Broch, H.B. (2003). Embodied play and gender identities in competitive handball for children in Norway. In E.P. Archetti \& N. Dyck (Eds.), Dane and embodied identities (pp. 75-93). Oxford: Berg Publishers.

De Backer, M., Vande Broek, G., \& Ceux, T. (2008). The influence of athletes' perceived justice of the coach on the intrinsic motivation and satisfaction of top handball and volleyball players. Leuven, Belgium: Catholic University.

DePaulo, B.M., \& Rosenthal, R. (1979). The structure of nonverbal decoding skills. Journal of Personality, 47, 506-517.

Deveney, S. (2007). Listen the (bleep) up! Sporting news, 231(13), 28-29.

Dosil, J. (2006). The sport psychologist's handbook: A guide for sport-specific performance enhancement. Chichester, UK: John Wiley \& Sons.

Greenspan, M.J., \& Feltz, D.F. (1989). Psychological interventions with athletes in competitive situations: A review. The Sport Psychologist, 3, 219-234.

Hoffman, J.D. (2000). Sport-confidence and perceptions of coaching behavior of male and female high school basketball players (Master's thesis). Springfield College, Springfield, MA.

Horn, T.S. (1985). Coaches' feedback and changes in children's perceptions of their physical competence. Journal of Educational Psychology, 77, 174-186. 
Jowett, S., \& Cockerill, I.M. (2002). Incompatibility in the coach-athlete relationship. In I.M. Cockerill (Ed.), Solutions in sport psychology (16-31). London: Thomson Learning.

Jowett, S., \& Chaundy, V. (2004). An investigation into the impact of coach leadership and coach-athlete relationship on group cohesion. Group Dynamics, 8, 302-311.

Jowett, S., \& Don Carolis, G. (2003). The coach-athlete relationship and perceived satisfaction in team sports. In R. Stelter (Ed.), XIth European Congress of Sport Psychology proceedings, 83-84. Copenhagen: Det Samfundsvidenskabelige Fakultets.

Kazdin, A.E. (1981). Drawing valid inferences from case studies. Journal of Consulting and Clinical Psychology, 49, 183-192.

Kazdin, A.E. (1982). Single case research designs, methods for clinical and applied settings. New York: Oxford University.

Kenow, L.J., \& Williams, J.M. (1992). Relationship between anxiety, self-confidence, and the evaluation of coaching behaviors. The Sport Psychologist, 6, 344-357.

Kenow, L.J., \& Williams, J.M. (1999). Factor structure of the coaching behavior questionnaire and its relationship to anxiety and self-confidence. Journal of Sport Behavior, 22(2), 251-259.

Littlepage, G., \& Pineault, T. (1978). Verbal, facial and paralinguistic cues to the detection of truth and lying. Personality and Social Psychology Bulletin, 4, 461-464.

Mageau, G.A., \& Vallerand, R.J. (2003). The coach-athlete relationship: A motivational model. Journal of Sports Sciences, 21, 883-904.

Martens, R., Burton, D., \& Vealey, R. Bump, L., \& Smith, D. (1990). The development of the Competitive State Anxiety Inventory-2 (CSAI-2). In R. Martens, R.S. Vealey, \& D. Burton (Eds.), Competitive anxiety in sport (117-190). Champaign, IL: Human Kinetics.

Mignault, A., \& Chaudhuri, A. (2003). The many faces of a neutral face: Head tilt and perception of dominance and emotion. Journal of Nonverbal Behavior, 27(2), 111-132.

Olympiou, A., Jowett, S., \& Duda, J.L. (2004, December). Motivational climates and the coach-athlete relationship as predictors of athletes' perceptions of passion for sport. The 1st International Conference on Quality of Life and Psychology, Aristotle University of Thessaloniki, Greece.

Olympiou, A., Jowett, S., \& Duda, J.L. (2005). Psychological needs as mediators of social contexts and role ambiguity. Annual Conference of the British Psychological Society, Manchester, UK.

Passer, M.W. (1988). Determinants and consequences of children's competitive stress. In F.L. Smoll, R.A. Magill, \& M.J. Ash (Eds.), Children in sport (203-227). Champaign, IL: Human Kinetics.

Pavlovic, S. (2008). Five steps to an effective halftime. Coach and Athletic Director, 7, 46-47.

Poczwardowski, A., Barott, J.E., \& Peregoy, J.J. (2002). The athlete and coach: Their relationships and its meaning - Methodological concerns and research process. International Journal of Sport Psychology, 33, 98-115.

Smith, R.E., Smoll, F.L., \& Cumming, S.P. (2007). Effects of a motivational climate intervention for coaches on young athletes' sport performance anxiety. Journal of Sport \& Exercise Psychology, 29, 39-59.

Smith, R.E., Smoll, F.L., Hunt, E.B., \& Curtis, B. (1979). Coach effectiveness training: A cognitive behavioral approach to enhancing relationship skills in youth sports coaches. Journal of Sport Psychology, 1, 59-75.

Smoll, F.L., \& Smith, R.E. (1989). Leadership behaviors in sport: A theoretical model and research paradigm. Journal of Applied Social Psychology, 19, 1522-1551.

Smoll, F.L., \& Smith, R.E. (2006). Enhancing coach-athlete relationships: Cognitive-behavioral principles and procedures. In J. Dosil (Ed.), The sport psychologist's handbook (19-37). Chichester, UK: John Wiley \& Sons.

Smoll, F.L., Smith, R.E., Barnett, N.P., \& Everett, J.J. (1993). Enhancement of children's self-esteem through social support training for youth sport coaches. The Journal of Applied Psychology, 78, 602-610. 
Smoll, F.L., Smith, R.E., \& Hunt, E. (1978). Toward a mediational model of coach-players relationships. Research Quarterly, 49, 528-541.

Sousa, C., Smith, R.E., \& Cruz, J. (2008). An individualized behavioral goal-setting program for coaches. Journal of Clinical Sport Psychology, 2, 258-277.

Van Buggenhout, J., Papaioannou, A., \& Vanden Auweele, Y. (2003). Interventions in the feedback skills of the coaches to improve the motivational climate perceived by the athletes in a boys handball team. Leuven: Catholic University Leuven.

Vergeer, I. (2000). Interpersonal relationships in sport: From nomology to idiography. International Journal of Sport Psychology, 31, 578-583.

Wish, M. (1976). Modality Differences in Perceptions of Communications. Conference record of the 1976 National Telecommunication Conference, Dallas, TX.

Wylleman, P. (2000). Interpersonal relationships in sport: Uncharted territory in sport psychology research. International Journal of Sport Psychology, 31, 555-572.

Zetou, E., Kourtesis, T., Giazitzi, K., \& Michalopoulou, M. (2008). Management and content analysis of timeout during volleyball games. International Journal of Performance Analysis in Sport, 8(1), 44-55.

Zuckerman, M., DePaulo, B.M., \& Rosenthal, R. (1980). Humans as lie-detectors. The Journal of Communication, 30, 129-139. 